\title{
Motivações de expositores brasileiros e estrangeiros em eventos internacionais
}

\section{Motivations of brazilians and foreigners exhibitors in international fairs}

\author{
Erica Piros Kovacs ${ }^{1}$ \\ Brigitte Renata Bezerra Oliveira ${ }^{2}$ \\ Steven Paul Smrekar Albuquerque ${ }^{3}$
}

\section{Resumo}

A atividade internacional que mais fortemente está associada ao aumento da competitividade exportadora da empresa é a participação assídua em feiras internacionais. Neste artigo, o objetivo é identificar as principais motivações que estimulam a participação de expositores brasileiros e estrangeiros em feiras internacionais. Os dados foram coletados durante a realização do Salão Internacional de Alimentação (SIAL), em Paris, e por e-mail. A amostra é composta por 67 empresas oriundas de nove países diferentes. Foram utilizadas técnicas estatísticas descritivas, análise fatorial e teste $T$ de comparação de médias. Os resultados indicam que as principais motivações para a participação em feiras internacionais estão relacionadas à melhoria da imagem da empresa, estabelecimento de parcerias e venda de produtos. $\mathrm{Na}$ análise fatorial, as 29 motivações diferentes foram resumidas a cinco fatores, a saber: fortalecimento da imagem e relacionamento; busca de vantagem competitiva; motivação da equipe e análise da concorrência; busca de novos negócios e parcerias; e relacionamento com fornecedores. Verificase que os expositores brasileiros têm menos experiência do que os estrangeiros na participação em feiras e quantidade de viagens internacionais e que há diferenças entre algumas de suas motivações.

Doutora em Administração, Universidade Federal de Pernambuco, UFPE, professora Adjunta do curso de Administração Universidade Federal Rural de Pernambuco - UFRPE - Brasil ericapk@hotmail.com

2 Doutora em Administração, Universidade Federal de Pernambuco, UFPE. Professora Assistente da Universidade Federal Rural de Pernambuco - UFRPE - Brasil - renataboliveira@gmail.com

3 Mestre em Administração. Universidade Federal de Pernambuco, UFPE - Brasil stevensmrekar@hotmail.com 
Palavras-chave: Feiras internacionais. Motivações. Expositores brasileiros. Expositores estrangeiros.

\section{Abstract}

The international activity that is most strongly associated with increased export competitiveness of the companies is the regular participation in international fairs. In this article, the aim is to identify the main motivations that encourage the participation of Brazilian and foreign exhibitors in international fairs. Data was collected during the course of SIAL in Paris and by email. The sample consists of 67 companies from nine different countries. Using descriptive statistics, factor analysis and testing mean comparison $t$ tests were used. The results indicate that the main motivations for participation in international fairs are related to improving the company's image, establishing partnerships and product sales. In the factor analysis, 29 different motives were summarized the five factors namely: strengthening the image and relationship; search for competitive advantage; Team motivation and competitive analysis; search for new business and partnerships; supplier relationships. It appears that the Brazilian exhibitors have less experience than foreign participation in fairs and amount of international travel and that there are differences between some of his motivations.

Keywords: International fairs. Motivations. Brazilian exhibitors. Foreign exhibitors.

\section{Introdução}

A arena internacional apresenta oportunidades e ameaças para as empresas que procuram competitividade em mercados globais e fronteiras internacionais. Apesar de essas empresas passarem a defrontar-se com problemas novos, diferentes do seu próprio mercado (PALÁCIOS; SOUZA, 2004, p.14), muitas tendem a se beneficiar substancialmente com essa expansão global (CZINKOTA; RONKAINEN; DONATH, 2004, p. 3).

Diferenças culturais e distâncias geográficas não mais constituem barreiras para os negócios e para a entrada em muitos mercados. A escolha de estratégias internacionais apropriadas permite que a empresa se transforme em uma corporação global (HITT; IRELAND; HOSKISSON, 2001, p. 316). Essa crescente abertura das fronteiras nacionais para o comércio internacional e investimento se traduziu em maiores níveis 
de competitividade, pressionando as empresas domésticas, que foram forçadas a competir contra as empresas internacionais (CONDO, 2000 p.2). Reforçadas pelo sucesso de empresas de países recentemente industrializados, economias emergentes estão mudando as suas políticas de crescimento para uma orientação externa, visando ao crescimento das exportações, em vez da permanência da orientação interna, que visava à substituição de exportação. Consequentemente, percebe-se atualmente uma presença crescente dos países emergentes na economia global integrada, onde estas passaram a buscar oportunidades no mercado internacional para ganhar e manter vantagens competitivas (AULAKH; KOTABE; TEEGEN, 2000, p. 342).

Tendo identificado novas oportunidades em qualquer parte do mundo, os concorrentes globais têm substituído os locais (KEEGAN, 2005). O crescente número de países adotando a ideologia do mercado livre, a transferência do processo de mudança do centro de gravidade econômico para os países em desenvolvimento, os avanços nas comunicações e as novas oportunidades de mercado, criadas por meio da abertura das fronteiras ao comércio, investimentos e transferência de tecnologias, são as forças que impulsionam a globalização e a internacionalização das empresas. Diante dessas tendências, os administradores, em empresas específicas, tomam decisões que resultam em maiores fluxos internacionais de capital, bens e ou conhecimento (GOVINDARAJAN; GUPTA, 2001), envolvendo a decisão sobre produtos, mercados, modo de entrada e velocidade da expansão devido à imperiosa adoção de uma estratégia global em oposição à estratégia doméstica (PORTER, 1999, p. 326).

Apesar de as características organizacionais e percepções de riscos pela gerência influenciarem o comportamento de internacionalização (a decisão de iniciar as exportações), o atual ambiente competitivo global exige aplicações proativas específicas de estratégias de exportação para atingirem sucesso em mercados estrangeiros (AULAKH; KOTABE; TEEGEN, 2000, p. 344). Atualmente, nenhum país é autossuficiente o bastante para produzir todos os bens e serviços de que sua população 
necessita. Aproximadamente $25 \%$ dos bens produzidos no mundo são exportados.

Como impulsionador dessas trocas, vem o marketing mix internacional, com destaque para o papel das feiras setoriais. Aimportância das feiras setoriais tem sido associada não apenas à função comercial e promocional, mas também à condição de contexto privilegiado para a obtenção de informações especializadas sobre clientes, tecnologia e mercados, fomentando o conhecimento de mercados internacionais e facilitando as primeiras exportações. Desempenha ainda papel especialmente relevante no desenvolvimento e internacionalização de pequenas e médias empresas por meio do processo de aprendizagem (SETUBAL; SOUZA 2004 p.129).

O principal órgão fomentado pelo governo brasileiro que investe na promoção comercial é a APEX-Brasil (Agência de Promoção de Exportações e Investimentos), que apoia técnica e financeiramente feiras e missões internacionais: eventos periódicos, setoriais ou multissetoriais, objetivando levar empresas brasileiras a expor e comercializar produtos e serviçosemespaçoapropriado, em que se podem realizaroutras atividades promocionais em paralelo.

Diante da importância da promoção como ferramenta de competitividade para as empresas e dos investimentos governamentais no Brasil, busca-se avaliar as motivações das empresas expositoras nestes eventos, para que, no seu planejamento, possam adequar as estratégias promocionais às expectativas das empresas.

Diante da baixa inserção das empresas brasileiras no mercado internacional, a questão de pesquisa é: há diferenças nas motivações entre empresas brasileiras e estrangeiras para a participação de feiras internacionais?

Nesse mister, o objetivo da pesquisa é identificar os principais motivos que levam os expositores de feiras internacionais a participarem desses eventos. 
A temática de que trata este estudo é de significativa relevância, tanto no contexto acadêmico quanto gerencial. A pesquisa acerca dos motivos que levam as empresas a participarem desses eventos pode ser uma ferramenta gerencial útil no desenvolvimento de missões técnicas, comerciais, e na organização e apoio de feiras internacionais. $O$ conhecimento teórico-empírico acerca das motivações para participação em feiras setoriais de empresas genuinamente brasileiras, comparandoas com empresas estrangeiras, pode ser valioso nas decisões de alocação de recursos e estimulante da atividade exportadora no país, proporcionando, tanto à academia quanto às organizações, maior entendimento das operações internacionais originadas no Brasil, com ênfase nos elementos do marketing mix detalhados na próxima seção.

\section{Referencial teórico}

\subsection{O mix de marketing internacional}

Segundo Keegan e Green (1999, p. 318-433), os fatores analisados para elaboração da estratégia de marketing voltada para o mercado internacional são:

- produtos existentes, suas alterações necessárias ou lançamento de novos produtos com as características adequadas;

- definição da estratégia de preços para os diversos mercados, em função do produto escolhido e suas características;

- escolha dos mercados e definição da estratégia de distribuição;

- elaboração e adequação da comunicação e imagem do produto para o mercado no qual se pretende atuar.

Para Sustar e Sustar (2005, p. 304), as decisões sobre o mix de marketing - preço, distribuição, produto e promoção comercial - não são diferentes daquelas feitas para o mercado local. A diferença é que o contexto de cada país no qual se toma a decisão é diferente. Percebese a necessidade de adequação da estratégia do mix de marketing para 
cada mercado no qual a empresa deseja atuar. Discorre-se sobre os quatro elementos do mix de marketing no contexto internacional a seguir.

\subsubsection{Decisões de produto internacional}

Um dos principais fatores para definição da estratégia de marketing, segundo Keegan e Green (1999), é a definição do produto adequado para o mercado no qual se pretende atuar. Para tanto, é necessário adequar os produtos existentes às necessidades locais, ou mesmo criar novos produtos visando suprir a demanda específica de cada mercado. As características intrínsecas ao produto podem ser classificadas de três formas distintas, em função de suas utilidades e demandas em mercados distintos. Segundo Keegan e Green (1999, p. 321-324), essa divisão serve para definir que estratégia e posicionamento devem ser utilizados para a adequação do composto de marketing à realidade do novo mercado.

- Produtos locais: são aqueles produtos criados, ou definidos, para atuação apenas em um mercado local;

- Produtos internacionais: são aqueles que podem ser vendidos em diversos mercados sem necessidade de adaptações;

- Produtos globais: são aqueles elaborados para atender às demandas do mercado global, com características que atendam às demandas dos consumidores localizados nos mais diferentes mercados.

Um produto pode ser definido como uma coleção de atributos físicos, psicológicos, de utilidade e simbólicos que, coletivamente, proporcionam satisfação e/ou benefícios para um comprador ou usuário (KEEGAN, 2005 p.249), e pode ser considerado o elemento mais importante de um programa de marketing. Os profissionais de marketing global enfrentam o desafio de formular uma estratégia internacional coerente de produto para as suas empresas. Duas posturas extremas são possíveis no que concerne às opções sobre os produtos e serviços a serem comercializados internacionalmente (PALÁCIOS; SOUSA, 2004, p. 108): estandardizar ou padronizar completamente, objetivando 
a redução de custos e melhoria de qualidade, conforme preconizado por Levitt (1983), mais provável em países que dispõem do mesmo nível de desenvolvimento econômico (WILD, WILD, HAN, 2006 p. 403); ou adaptar completamente para atender às exigências do mercado a ser atingido. No entanto, esses dois extremos podem ser considerados como pontos de um continuum, com a possibilidade de adoção de categorias de produto local, nacional, internacional e global (KEEGAN, 2005 p. 250), ou ainda podem ser utilizados concomitantemente pela mesma empresa (VRONTIS, KITCHEN, 2005). O produto local está disponível apenas em uma parte de um mercado nacional. O nacional, por sua vez, é aquele que, no contexto de uma empresa específica, é oferecido em um único mercado nacional. Os produtos internacionais e as marcas globais são oferecidos em mercados multinacionais e regionais, e os produtos globais são oferecidos em todas as regiões do mundo. No entanto, a decisão de marca deve ser analisada com cautela, visto que nomes do mercado de origem podem ser ofensivos se não forem pesquisados e selecionados cuidadosamente (WILD, WILD, HAN, 2006 p. 405).

A decisão de modificar ou não o produto ou serviço depende do mix de produto e de mercado da empresa, como também da idade do padrão de consumo (WHITELOCK, 2001 p.32), não sendo passível de generalização. A autora ainda advoga que produtos mais recentes tendem a ser mais "homogeneizáveis" do que os produtos mais antigos, que já se encontram enraizados na cultura da nação. No processo de internacionalização, os bens de consumo tendem a requerer mais adaptação do que produtos industriais, em que as necessidades do cliente e a concorrência são as principais influências para a adoção da mudança. Tais modificações relacionam-se à forma de utilização do produto, etiquetagem, qualidade, embalagem e estilo, em ordem decrescente de importância (WARD, 1973 p. 83-85). As preferências dos consumidores por diversos fatores, tais como sabores e cores, os fatores de custo, as leis e regulamentos da região a ser explorada e a compatibilidade do produto com o ambiente no qual será utilizado fazem parte do processo decisório sobre a adaptação dos produtos (KEEGAN, 2005 p. 258-259). Percebe-se também alterações do posicionamento do 
produto em mercados internacionais, sejam estas gerais: por atributo ou benefício, qualidade/preço, uso e aplicação e uso/usuário, ou as consideradas adicionais: high-tech ou high-touch (KEEGAN, 2005), como também a influência do país de origem nos valores percebidos pelos consumidores sobre o produto (WILD, WILD, HAN, 2006 p. 406).

\subsubsection{Decisões de preço internacional}

Para o marketing, a concepção de preço está associada ao conceito de valor percebido ou à soma dos benefícios sobre a soma dos custos, sob a ótica do cliente: tudo que o consumidor percebe ter dado ou sacrificado para obter o produto (SIMONSON, I.; NOWLIS, S.; LEMON, 1993; URDAN; URDAN, 2006, p. 184), seja esse sacrifício monetário ou não monetário, relacionado ao tempo, à energia ou às questões psicológicas.

As teorias clássicas do comportamento do consumidor assumem que cada alternativa de compra é associada a um valor específico, e o consumidor seleciona a opção de acordo com o maior nível de agregação de valor. No marketing mix, o preço tem natureza distinta dos demais elementos: enquanto os outros Ps criam valor para o cliente, implicando em desembolso de dinheiro para a empresa, o preço permite que seja obtida parte do valor propiciado como recompensa monetária, dentro da relação de troca. Em outras palavras, é a contrapartida que a empresa cobra do consumidor pelo que oferece a ele. No processo de precificação de produtos, as empresas consideram não apenas a análise dos custos de produção, mas também da concorrência, da demanda e do consumidor (URDAN; URDAN, 2006).

No contexto global, é possível afirmar que os ajustes locais podem influenciar as preferências dos consumidores e, por conseguinte, o valor percebido e o preço dos produtos (SIMONSON, I.; NOWLIS, S.; LEMON, 1993). Tais preferências, ligadas essencialmente aos elementos não monetários, são impactadas por valores nacionais como cultura e educação, renda, concentração geográfica, nível de instrução, tolerância ao risco, ambiente econômico e legal, infraestrutura de distribuição, 
características e comportamento do consumidor (THEODOSIOU; KATSIKEAS, 2001).

Maxwell (2001) testou a homogeneidade versus a heterogeneidade do consumo global em um estudo cross-cultural do modelo preço/marca. Foram comparados padrões provenientes dos EUA, país desenvolvido e com características já estabelecidas de consumo, e da Índia, mercado emergente e com padrões em construção. De acordo com seus achados, quando comparados aos americanos, os indianos de fato têm uma baixa percepção de qualidade da marca. Ademais, são mais propensos a economizar, incorrendo em sentimentos de culpa associados ao ato do consumo.

A estratégia de preço para uma firma deve estar combinada com a forma ampla de sua estratégia internacional (WILD; WILD; HAN, 2006, p. 417-419). Os autores defendem que um produto típico de liderança custo em uma indústria doméstica dificilmente adota um preço premium em novos mercados, graças à ausência de características especiais e à ênfase na funcionalidade do produto. Por outro lado, uma empresa que segue a estratégia de diferenciação, no contexto global, tende a adotar o mesmo comportamento. Dentre as políticas de precificação, a firma pode seguir a estratégia world wide, em que um preço de venda único é estabelecido para todos os mercados internacionais, também chamada de extensão/etnocêntrica, política dual, ou adaptação/policêntrica, em que diferentes preços são praticados para diferentes países, geralmente maiores no hospedeiro (KEEGAN, 2005; WILD; WILD; HAN, 2006). Os problemas da política world wide referem-se aos custos que não são os mesmos entre os países. Ademais, mesmo para exportação, as taxas e tributos que incidem sobre os produtos importados são diferenciados, incorrendo em diferenças nos preços finais. Por outro lado, a aplicação da política dual exige que as empresas tenham claramente definidas as características e necessidades inerentes aos consumidores domésticos e internacionais.

Diversas são as fontes de influências ambientais em decisões de determinação de preços (KEEGAN, 2005). Variáveis como flutuações 
da moeda, cláusulas de taxas de câmbio, inflação, controles e subsídios governamentais, o comportamento competitivo e as relações esperadas entre preço e qualidade devem ser consideradas. Por vezes, as empresas fazem uso da procedência como instrumento estratégico de fixação de preço, sendo essa ação particularmente presente naqueles produtos que são associados a países específicos, como o chocolate suíço, o champanhe francês, o café colombiano ou a produção de vinhos brasileiros na serra gaúcha (EMBRAPA, 2006).

\subsubsection{Decisões de distribuição internacional}

Canais de distribuição de marketing podem ser definidos como redes organizadas de instituições, agências, empresas, pessoas e outros recursos, que, de forma combinada, desempenham as mais diversas atividades requeridas para conectar produtores e usuários e realizar trocas de valor com o mercado (KEEGAN, 2005, p. 300; URDAN; URDAN, 2006, p. 127), dentro do país alvo (GABRIELSON; KIRPALANI; LUOSTARINEN, 2002). O propósito central dos canais de marketing está associado à criação de utilidade para os clientes quanto a tempo e lugar. Dentre as principais categorias de utilidade de canal em relação ao cliente, estão (KEEGAN, 2005, p. 301): 1) ponto: disponibilidade do produto em local acessível; 2) tempo: disponibilidade do produto quando desejado; 3) forma: o produto está processado, preparado e pronto para o uso em condições adequadas; e 4) informação: comunicação geral sobre as características e benefícios do produto.

As decisões de distribuição são multidimensionais, por considerarem simultaneamente as características ambientais, dos intermediários, dos clientes e dos produtos, como grau de padronização, perecibilidade, tamanho e preço. Questionamentos como onde estão localizados os clientes potenciais, quais são suas necessidades e preferências de acesso e quais são suas exigências de informação (KEEGAN, 2005, p. 301) devem ser continuamente monitorados, Características sociodemográficas, como distribuição geográfica, renda, hábitos de compra e consumo, podem variar de país para país, 
requerendo, portanto, diferentes enfoques de canal. Esses enfoques estão associados à própria filosofia da empresa de padronizar ou adaptar sua oferta de valor para a conquista de novos mercados.

Quanto à propriedade do canal, a empresa deve decidir se fará uso de forças de vendas e lojas próprias, caracterizando um envolvimento direto, ou trabalhar em conjunto com agentes independentes, representante comercial autônomo, atacadistas e distribuidores (URDAN; URDAN, 2006). Por outro lado, a intensidade da distribuição ou quantidade de agentes em cada nível do canal em relação à área geográfica servida define os modos de distribuição intensiva (maximizar o número de produtores encarregados de escoar o produto), seletiva (no qual o produtor opera com um conjunto reduzido de pontos de venda) e exclusiva (os membros do canal trabalham apenas com bens de um único produtor).

O modelo processual de internacionalização reconhece dois grupos principais de operações de marketing, os quais formam a base para as estratégias de canal utilizadas em novos mercados: 1) operações de exportação direta, indireta e própria; e 2) subsidiárias de vendas e marketing (GABRIELSON; KIRPALANI; LUOSTARINEN, 2002). Em linha consonante, Johanson e Vahlne (1977) afirmam que dentre os estágios desse processo estão atividades esporádicas de exportação, uso de representantes e agentes, estabelecimento de subsidiárias de vendas até implantação de unidades fabris no país hospedeiro. À medida que o processo de internacionalização evolui por entre os estágios, há um maior comprometimento das empresas com a atividade internacional, representado pela efetividade da alocação dos recursos e nível de especialização. Segundo a proposição de Gabrielson, Kirpalani e Luostarinen (2002), um baixo grau de internacionalização aumenta a probabilidade de fazer uso de estratégias de canais indiretos.

Nessemister, cabe mencionarque estas aliançascomintermediários e aprendizado organizacional são pontos de destaque dentre as pesquisas de negócios internacionais (WANG; NICHOLAS, 2005), sejam focadas na criação de conhecimento interno ou aprendizado por 
firmas independentes em fusões e aquisições, joint-ventures e alianças sem participação do patrimônio líquido. A literatura emergente nesse tipo de aprendizado direciona esforços para transferência e replicação do conhecimento por diversas perspectivas, incluindo como ocorre o fluxo por entre parceiros em um sistema mútuo de cooperação. Em mercados competitivos, alianças são estratégias para operações internacionais nas quais as firmas apropriam retornos acima da média sob recursos heterogêneos e insubstituíveis, decorrendo a raridade e superioridade competitiva proporcionada pela estratégia de distribuição (BARNEY, 1986, 2002; PRAHALAD; HAMEL, 1990). É particularmente útil quando a firma não dispõe de competência suficiente para comercializar ou produzir no mercado externo, além da pouca ou nenhuma familiaridade com atributos culturais, econômicos, político-legais e especificidades das expectativas e valores da demanda (BARNEY, 2002; HITT; IRELAND; HOSKISSON, 2002; WILD; WILD; HAN, 2006).

Para ser um competidor real na economia global, uma organização precisa ser também uma cooperadora de confiança (MORGAN; HUNT, 1994). Muitas companhias multinacionais estão aprendendo que precisam colaborar para competir. Cultivar o relacionamento, nesse sentido, refere-se às atividades direcionadas ao estabelecimento, desenvolvimento e manutenção do sucesso em trocas com os parceiros (MORIARTY; MORAN, 1990; SETHURAMAN; ANDERSON; NARUS, 1988). Confiança e comprometimento são chaves porque encorajam as organizações a: (1) trabalharem na preservação de investimentos em relacionamentos por meios da cooperação com os parceiros; e (2) resistirem às alternativas de curto prazo atrativas em favor dos benefícios esperados em longo prazo em permanecer com os parceiros existentes (MORGAN; HUNT, 1994).

Para Quelch e Klein (1996, p. 66), o valor agregado pelo canal deixou de ser baseado na capacidade física de distribuição de mercadorias, passando a ser coleta, interpretação e disseminação de informações específicas sobre determinado mercado. Porém, segundo Geyshkens et al. (2002, p.106), quanto mais canais uma empresa tiver, 
menor será a importância da implantação da internet como canal de distribuição.

Algumas informações são fundamentais para transmitir confiança e credibilidade para os clientes. Para White (1997, p. 382-383), fatores como linguagem adequada, disponibilidade de envio internacional, conversão de preços para a moeda local do consumidor, informação sobre custos de envio, acompanhamento da entrega pelo cliente e a disponibilidade do produto no mercado local se tornam necessários para a internacionalização da empresa.

\subsubsection{Decisões de promoção internacional}

A promoção de vendas é qualquer programa ao consumidor ou ao comércio, de duração limitada, que agregue valor tangível a um produto ou marca e pode consistir de: táticas de preços promocionais, competições, concursos e jogos, versões especiais e premium, apresentações de revendedores, materiais de ponto de venda, promoções cruzadas e casadas, embalagem, feiras e eventos comerciais e patrocínio, e tem como propósito estimular os clientes a experimentar um produto ou aumentar a demanda de consumo (KEEGAN, 2005 p. 347). Proporciona um incentivo tangível aos compradores e a redução de risco percebido que os compradores possam associar à compra do produto. Os esforços da empresa em atingir canais de distribuição e consumidores-alvo por meio de comunicações, tais como vendas pessoais, propaganda, relações públicas e marketing direto, são chamados de mix de promoção (WILD, WILD, HAN, 2006 p.408), e a utilização dos elementos do mix depende da estratégia que a empresa se propõe a alcançar (PALACIOS, SOUSA, 2004 p 175).

A promoção de vendas internacional e a propaganda requerem adaptação às condições específicas do país, assim como a utilização de marketing direto exige a análise prévia da infraestrutura disponível, para que funcione de forma eficaz. As feiras, eventos e exposições são cada vez mais importantes no mercado internacional e têm recebido pouca atenção pela academia. Os motivos da participação (vender ou comprar) 
as formas de participação (expositores e visitantes) levam a uma nova perspectiva de comportamentos de compra e venda (HANSEN, 1996 p. 42). A atividade internacional que mais fortemente está associada ao aumento da competitividade exportadora da empresa é a participação assídua em feiras internacionais, onde o administrador conhece os seus concorrentes e clientes, refletindo numa visão mais ampla do mercado global (BRITTO, 2004 p. 143).

A importância das feiras setoriais tem sido associada não apenas à função comercial e promocional, mas também à condição de contexto privilegiado para a obtenção de informações especializadas sobre clientes, tecnologia e mercados. Desempenha ainda papel especialmente relevante no desenvolvimento e internacionalização de pequenas e médias empresas por meio do processo de aprendizagem (SETUBAL; SOUZA 2004 p.129).

O principal órgão fomentado pelo governo que apoia a promoção comercial é a APEX-Brasil (Agência de Promoção de Exportações e Investimentos), que apoia técnica e financeiramente feiras e missões internacionais: eventos periódicos, setoriais ou multissetoriais, objetivando levar empresas brasileiras para expor e comercializar produtos e serviços em espaço apropriado, em que se podem realizar outras atividades promocionais em paralelo. Criada em novembro de 1997, a APEX funcionou como uma Gerência Especial do Sebrae Nacional até 6 de fevereiro de 2003. Nesta data, passou a ser denominada APEX-Brasil, constituindo-se em um Serviço Social Autônomo ligado ao Ministério do Desenvolvimento, Indústria e Comércio Exterior.

Alguns autores, tais como Hansen (1996 e 2004), Oshen (1989) e Smith e Smith (1999) elaboraram escalas para mensuração de motivações e desempenho para feiras internacionais. Os itens da escala, utilizados para elaboração do questionário aplicado nesta pesquisa, são apresentados no Quadro 1. 
Quadro 1 - Motivos para participação em feiras internacionais

\begin{tabular}{|c|c|c|c|}
\hline Smith, Smith (1999) & Hoshen (1989) & Hansen (1996) & Hansen (2004) \\
\hline $\begin{array}{l}\text { - Participar de eventos, } \\
\text { palestras ou seminários } \\
\text { - Discutir problemas } \\
\text { com fornecedores } \\
\text { - Treinar e desenvolver } \\
\text { a capacidade de } \\
\text { vendas } \\
\text { - Encontrar novos } \\
\text { fornecedores } \\
\text { - Observar as } \\
\text { características de } \\
\text { outros produtos } \\
\text { - Acompanhar o } \\
\text { lançamento de novos } \\
\text { produtos } \\
\text { - Observar as } \\
\text { tendências do mercado } \\
\text { Fazer pedido de } \\
\text { produtos } \\
\text { - Decidir sobre } \\
\text { determinada compra } \\
\text { - Investir em } \\
\text { relacionamento com } \\
\text { atuais fornecedores }\end{array}$ & $\begin{array}{l}\text { - Tomar nota de } \\
\text { detalhes técnicos } \\
\text { de produtos } \\
\text { concorrentes } \\
\text { - Tirar fotografia } \\
\text { dos produtos } \\
\text { concorrentes } \\
\text { - Buscar } \\
\text { produtos para } \\
\text { representações } \\
\text { - Procurar por } \\
\text { investidores em } \\
\text { potencial } \\
\text { - Procurar por } \\
\text { parceiros em } \\
\text { potencial }\end{array}$ & $\begin{array}{l}\text { - Criar uma melhor } \\
\text { imagem de minha } \\
\text { empresa } \\
\text { - Conseguir } \\
\text { informações dos } \\
\text { concorrentes } \\
\text { - Testar novos } \\
\text { produtos } \\
\text { - Dar atenção aos } \\
\text { consumidores atuais } \\
\text { - Vender os produtos } \\
\text { atuais } \\
\text { - Introduzir } \\
\text { novos produtos } \\
\text { ou apresentar } \\
\text { alterações nos } \\
\text { atuais } \\
\text { - Aumentar o manter } \\
\text { a moral da empresa } \\
\text { Identificar novos } \\
\text { clientes potenciais }\end{array}$ & $\begin{array}{l}\text { - Convencer os } \\
\text { consumidores que } \\
\text { minha empresa é } \\
\text { sólida } \\
\text { - Para mostrar aos } \\
\text { consumidores que } \\
\text { somos melhor que a } \\
\text { concorrência } \\
\text { - Aumentar a } \\
\text { participação de } \\
\text { mercado de meus } \\
\text { produtos } \\
\text { - É uma vantagem } \\
\text { em relação aos } \\
\text { concorrentes que } \\
\text { não participam } \\
\text { desta feira } \\
\text { - Motivar ao pessoal } \\
\text { de minha empresa } \\
\text { - Motivar os clientes }\end{array}$ \\
\hline
\end{tabular}

Fonte: Autores acima alinhados.

Ao compararem a participação em feiras internacionais e nacionais de empresas japonesas, Smith, Hama e Smith (2003) identificaram que os motivos para exposição considerados importantes para uma intenção de nova participação em feiras foram os mesmos, independentemente da localização geográfica da feira. Contudo, nas feiras realizadas dentro do país, percebe-se uma maior preocupação em observar tendências de mercado, enquanto nas feiras fora do país os expositores consideram uma participação de sucesso quando as motivações de interação com fornecedores, informações de compras e busca de informações sobre tendências são combinadas. 


\section{Método de pesquisa}

Esta pesquisa tem caráter exploratório. O objetivo deste estudo foi alcançar uma compreensão sobre a motivação das empresas a participarem de feiras internacionais, com uma amostra não representativa, por meio de uma coleta de dados estruturada (MARCONI; LAKATOS, 2002, p. 20). A coleta de dados ocorreu em duas fases. A primeira foi durante o Salão Internacional de Alimentação (SIAL) que ocorreu em 2014, em Paris, e questionários impressos foram entregues pessoalmente para os respondentes. Nessa etapa, foram respondidos 38 questionários. Na segunda fase, foram utilizados catálogos distribuídos durante o evento, para construir uma lista de endereços eletrônicos. Foram enviados 600 e-mails com o questionário anexado, sendo obtidas 29 respostas.

Dentre as vantagens apresentadas por Cooper e Schindler (2000, p. 261) na aplicação destes surveys autoadministrados, as principais são: custo mais baixo, permissão de contato com respondentes inacessíveis de outra forma, possibilidade de maior cobertura geográfica sem aumento significativo nos custos, percepção de anonimato e respondente com mais tempo para pensar sobre a pergunta.

O questionário foi elaborado no idioma inglês e teve como base o referencial teórico pesquisado, sendo as motivações oriundas dos trabalhos desenvolvidos por Hansen(1996 e 2004), Hoshen(1989)e Smith e Smith (1999), cujo conteúdo constou apenas de questões fechadas, abordando a importância relativa das motivações do participante de feiras internacionais. Os itens de importância foram mensurados por meio da escala tipo Likert, de 1 a 5, considerando 1 como menos importante e 5 como mais importante. Essa escala de classificação somatória consiste de afirmações que expressam atitudes favoráveis ou desfavoráveis ao objeto de interesse (COOPER; SCHINDLER, 2001, p. 202).

As alternativas presentes na versão final do questionário são apresentadas no Quadro 2. 
Quadro 2 - Itens apresentados no instrumento de coleta de dados

\begin{tabular}{|c|c|}
\hline Alternativas & Label \\
\hline Participar de eventos, palestras ou seminários & Q0 \\
\hline Convencer os consumidores que minha empresa é sólida & Q1 \\
\hline Para mostrar aos consumidores que somos melhor que a concorrência & Q2 \\
\hline Aumentar a participação de mercado de meus produtos & Q3 \\
\hline Discutir problemas com fornecedores & Q4 \\
\hline Treinar e desenvolver a capacidade de vendas & Q5 \\
\hline Criar uma melhor imagem de minha empresa & Q6 \\
\hline Encontrar novos fornecedores & Q7 \\
\hline É uma vantagem em relação aos concorrentes que não participam desta feira & Q8 \\
\hline Observar as tendências do mercado & Q9 \\
\hline Conseguir informações dos concorrentes & Q10 \\
\hline Identificar novos clientes potenciais & Q11 \\
\hline Aumentar o manter a moral da empresa & Q12 \\
\hline Introduzir novos produtos ou apresentar alterações nos atuais & Q13 \\
\hline Investir em relacionamento com atuais fornecedores & Q14 \\
\hline Procurar por parceiros em potencial & Q15 \\
\hline Procurar por investidores em potencial & Q16 \\
\hline Decidir sobre determinada compra & Q17 \\
\hline Motivar os clientes & Q18 \\
\hline Motivar ao pessoal de minha empresa & Q19 \\
\hline Fazer pedido de produtos & Q20 \\
\hline Buscar produtos para representações & Q21 \\
\hline Observar as características de outros produtos & Q22 \\
\hline Acompanhar o lançamento de novos produtos & Q23 \\
\hline Vender os produtos atuais & Q24 \\
\hline Dar atenção aos consumidores atuais & Q25 \\
\hline Tirar fotografia dos produtos concorrentes & Q26 \\
\hline Tomar nota de detalhes técnicos de produtos concorrentes & Q27 \\
\hline Testar novos produtos & Q28 \\
\hline
\end{tabular}

Fonte: Adaptado de Hansen (1996 e 2004), Hoshen (1989) e Smith e Smith (1999).

Os labels serão utilizados nas tabelas seguintes como forma de identificar a alternativa. 
Foram obtidos 30 questionários respondidos por empresas brasileiras e 37 internacionais, de países como África do Sul, Coreia, Grécia, Itália e Singapura. A análise dos dados foi quantitativa, por meio de ferramentas estatísticas, utilizando-se o SPSS 15.

\section{Análise dos dados}

A distribuição dos países de origem das empresas respondentes pode ser observada na Tabela 1.

Tabela 1- Países de origem das empresas respondentes

\begin{tabular}{l|c|c|c|c}
\hline & Frequency & Percent & Valid Percent & Cumulative Percent \\
\hline Brazil & 30 & 44,8 & 44,8 & 44,8 \\
\hline Greece & 3 & 4,5 & 4,5 & 49,3 \\
\hline France & 5 & 7,5 & 7,5 & 56,7 \\
\hline Italy & 9 & 13,4 & 13,4 & 70,1 \\
\hline Spain & 3 & 4,5 & 4,5 & 74,6 \\
\hline Korea & 7 & 10,4 & 10,4 & 85,1 \\
\hline Singapore & 2 & 3,0 & 3,0 & 88,1 \\
\hline Austria & 5 & 7,5 & 7,5 & 95,5 \\
\hline South Africa & 3 & 4,5 & 4,5 & 100,0 \\
\hline Total & 67 & 100,0 & 100,0 & \\
\hline
\end{tabular}

Fonte: Dados da pesquisa.

O perfil da amostra foi identificado inicialmente para entender o comportamento dos respondentes, sendo 93\% dos respondentes graduados, $96 \%$ do gênero masculino e $70 \%$ com cargo de gerência ou diretoria na empresa que trabalham. Todas as empresas pesquisadas atuam no comércio internacional. A exportação é a forma mais comum de atuação, utilizada por $80 \%$ das empresas. Apenas $5 \%$ das empresas possuem subsidiárias no exterior. Dentre as 37 empresas estrangeiras pesquisadas, 31 nunca negociaram com empresas brasileiras. As empresas pesquisadas possuem experiência na participação de feiras. Em apenas 3\% das empresas o evento pesquisado foi sua primeira participação. A maioria dos respondentes já participou de mais de 
8 feiras nos últimos cinco anos e $60 \%$ realizaram mais de 3 viagens internacionais nos últimos 12 meses.

No entanto, ao comparar os expositores brasileiros com os estrangeiros, percebe-se que estes têm mais experiência, conforme Tabela 2.

Tabela 2 - Quantidade de feiras como expositores nos últimos cinco anos

\begin{tabular}{l|c|c|c|c|c}
\hline \multicolumn{7}{|c}{ Quantidade de feiras como expositor nos últimos 5 anos } \\
\hline & None, it's the first & $\mathbf{2 - 3}$ times & 4-5 times & $\mathbf{6 - 8}$ times & More than 8 \\
\hline Brasileiros & 1 & 6 & 9 & 4 & 12 \\
\hline Estrangeiros & & 6 & & 8 & 21 \\
\hline & 1 & 12 & 9 & 12 & 33 \\
\hline
\end{tabular}

Fonte: Dados da pesquisa.

Os setores pesquisados são diversificados: 54\% têm mais de 100 funcionários e $70 \%$ são do setor produtivo. Contudo, percebe-se uma concentração de respostas do setor de bebidas, visto que $52 \%$ das empresas atuam na indústria de bebidas alcoólicas e não alcoólicas. Os segmentos pesquisados podem ser observados na Tabela 3.

Tabela 3 - Segmentos pesquisados

\begin{tabular}{l|c|c|c|c}
\hline & Frequency & Percent & Valid Percent & Cumulative Percent \\
\hline Alcoholic beverages & 17 & 25,4 & 25,4 & 25,4 \\
\hline Non alcoholic beverages & 18 & 26,9 & 26,9 & 52,2 \\
\hline Confectionary & 3 & 4,5 & 4,5 & 56,7 \\
\hline Dairy & 2 & 3,0 & 3,0 & 59,7 \\
\hline Preserved foods & 3 & 4,5 & 4,5 & 64,2 \\
\hline Fruits and vegetables & 1 & 1,5 & 1,5 & 65,7 \\
\hline Organic & 8 & 11,9 & 11,9 & 77,6 \\
\hline Seafood & 5 & 7,5 & 7,5 & 85,1 \\
\hline Software & 1 & 1,5 & 1,5 & 86,6 \\
\hline Others & 6 & 9,0 & 9,0 & 95,5 \\
\hline Shoes & 3 & 4,5 & 4,5 & 100,0 \\
\hline Total & 67 & 100,0 & 100,0 & \\
\hline
\end{tabular}

Fonte: Dados da pesquisa. 
Percebe-se que, dentre os motivos de participação, os mais importantes referem-se à melhoria de imagem, vendas de produtos existentes e busca de parceiros, o que pode ser observado na Tabela 6. Nota-se também uma preocupação tecnológica, ou seja, a identificação do que está surgindo de novo na concorrência. Os atributos menos importantes envolvem a participação de eventos paralelos em feiras, tais como palestras e seminários e os motivos relacionados a aquisição, tais como fazer pedidos de produtos, decidir sobre compras, discutir problemas com fornecedores ou buscar representações, refletindo que a motivação real não é comprar, e sim vender os seus produtos.

Tabela 4 - Motivações para participação em feiras dos respondentes

\begin{tabular}{|c|c|c|}
\hline & Média & Desvio-Padrão \\
\hline Criar uma melhor imagem de minha empresa & 4,32 & ,826 \\
\hline Procurar por parceiros em potencial & 4,17 & 1,431 \\
\hline Convencer os consumidores que minha empresa é sólida & 4,05 & ,968 \\
\hline Vender os produtos atuais & 3,96 & 1,160 \\
\hline Dar atenção aos consumidores atuais & 3,91 & 1,208 \\
\hline Observar as tendências do mercado & 3,86 & 1,158 \\
\hline Prospectar clientes & 3,83 & 1,009 \\
\hline $\begin{array}{l}\text { Tirar vantagem em relação aos concorrentes que não participam } \\
\text { desta feira }\end{array}$ & 3,74 & 1,149 \\
\hline Motivar os clientes & 3,70 & 1,122 \\
\hline $\begin{array}{l}\text { Para mostrar aos consumidores que somos melhor que a } \\
\text { concorrência }\end{array}$ & 3,70 & 1,095 \\
\hline Conseguir informações dos concorrentes & 3,61 & 1,226 \\
\hline Testar novos produtos & 3,58 & 1,371 \\
\hline Desenvolver novos produtos, segmentos de mercado & 3,55 & 1,438 \\
\hline Introduzir novos produtos ou apresentar alterações nos atuais & 3,52 & 1,368 \\
\hline Acompanhar o lançamento de novos produtos & 3,40 & 1,196 \\
\hline Encontrar novos fornecedores & 3,32 & 1,491 \\
\hline Investir em relacionamento com atuais fornecedores & 3,26 & 1,534 \\
\hline Motivar ao pessoal de vendas de minha empresa & 3,08 & 1,059 \\
\hline Observar as características de outros produtos & 3,02 & 1,183 \\
\hline Tomar nota de detalhes técnicos de produtos concorrentes & 2,97 & 1,334 \\
\hline
\end{tabular}




\begin{tabular}{l|c|c}
\hline Aumentar o manter a moral da empresa & 2,75 & 1,238 \\
\hline Treinar e desenvolver a capacidade de vendas & 2,74 & 1,253 \\
\hline Fazer pedido de produtos & 2,66 & 1,171 \\
\hline Discutir problemas com fornecedores & 2,57 & 1,403 \\
\hline Procurar por investidores em potencial & 2,50 & 1,403 \\
\hline Decidir sobre determinada compra & 2,49 & 1,382 \\
\hline Participar de eventos, palestras ou seminários & 2,47 & 1,629 \\
\hline Tirar fotografia dos produtos concorrentes & 2,46 & 1,511 \\
\hline Buscar produtos para representações & 2,35 & 1,452 \\
\hline
\end{tabular}

Fonte: Dados da pesquisa.

Com o objetivo de identificar grupo de fatores mais significativos na decisão de participar ou não de uma feira internacional, foi realizada uma análise fatorial exploratória, com o objetivo foi o de identificar variáveis latentes desconhecidas e construir um conhecimento mais sólido sobre o tema. Cinco fatores foram identificados, algumas variáveis que não obtiveram cargas significativas foram excluídas da análise. $\mathrm{O}$ resultado das análises pode ser observado na Tabela 5.

Tabela 5 - Análise fatorial exploratória

\begin{tabular}{|c|c|c|c|c|c|c|}
\hline Alternativas & Fator1 & Fator2 & Fator3 & Fator4 & Fator5 & Variávellatente \\
\hline Q1 & ,730 & - & - & - & - & \multirow{7}{*}{$\begin{array}{l}\text { Imagem e } \\
\text { relacionamentos }\end{array}$} \\
\hline Q6 & ,768 & - & - & - & - & \\
\hline Q13 & ,823 & - & - & - & - & \\
\hline Q15 &, 595 & - & - & - & - & \\
\hline Q18 & ,781 & - & - & - & - & \\
\hline Q25 & ,760 & - & - & - & - & \\
\hline Q28 & ,651 & - & - & - & - & \\
\hline Q8 & - & ,793 & - & - & - & \multirow{4}{*}{ Vantagemcompetitiva } \\
\hline Q9 & - & ,785 & - & - & - & \\
\hline Q10 & - & 877 & - & - & - & \\
\hline Q23 & - & ,749 & - & - & - & \\
\hline
\end{tabular}




\begin{tabular}{|c|c|c|c|c|c|c|}
\hline Q5 & - & - & ,832 & - & - & \multirow{5}{*}{$\begin{array}{l}\text { Motivação da } \\
\text { equipe e análise da } \\
\text { concorrência }\end{array}$} \\
\hline Q0 & - & - & ,703 & - & - & \\
\hline Q19 & - & - & ,606 & - & - & \\
\hline Q26 & - & - & ,839 & - & - & \\
\hline Q27 & - & - & ,806 & - & - & \\
\hline Q16 & - & - & - & ,749 & - & \multirow{4}{*}{$\begin{array}{l}\text { Novosnegócios e } \\
\text { parcerias }\end{array}$} \\
\hline Q17 & - & - & - & ,734 & - & \\
\hline Q21 & - & - & - & ,696 & - & \\
\hline Q22 & - & - & - & ,676 & - & \\
\hline Q4 & - & - & - & - & ,863 & \multirow{3}{*}{ Fornecedores } \\
\hline Q7 & - & - & - & - & ,682 & \\
\hline Q14 & - & - & - & - & 851, & \\
\hline
\end{tabular}

Fonte: Dados da pesquisa.

Foi identificado por meio da análise fatorial exploratória que os participantes de feiras internacionais têm basicamente cinco motivações:

1. Fortalecimento em imagem e relacionamentos - melhorar a imagem corporativa, convencer os clientes de que são melhores do que a concorrência, motivar os clientes e servi-los da melhor forma, além de buscar parcerias.

2. Competitividade - observar novas tendências de mercado e informações competitivas, além de considerar que se obtém maior vantagem competitiva do que os concorrentes que não estão expondo.

3. Motivação da equipe e análise da concorrência - treinamento e motivação da equipe de vendas, além da participação em eventos paralelos e análises técnicas dos produtos da concorrência.

4. Busca de negócios e parcerias - busca por investidores em potencial, produtos para representar e para comprar, além da análise dos atributos de produtos atuais.

5. Relacionamento com fornecedores - discutir problemas com fornecedores atuais, encontrar novos e investir nos relacionamentos. 
Observa-se, que, dentre os cinco fatores encontrados, o que apresenta menor explicação é o de fazer compras, corroborando com os motivos comerciais e de divulgação no mercado internacional.

Na comparação entre as motivações dos expositores brasileiros e estrangeiros, foram identificadas algumas diferenças por meio do teste T, apresentado na Tabela 6. Os brasileiros consideram mais importantes o treinamento e o desenvolvimento da capacidade de vendas, criação de uma melhor imagem da empresa, obtenção de vantagem em relação aos concorrentes que não participam (quiçá deve-se à baixa participação destas empresas brasileiras em feiras internacionais, o que torna por si só a exposição como fator de competitividade).

Tabela 6 - Diferentes motivações de expositores brasileiros e estrangeiros

\begin{tabular}{|c|c|c|c|c|}
\hline & & $\begin{array}{l}\text { Sig.T } \\
\text { Test }\end{array}$ & Mean & $\begin{array}{l}\text { Std. } \\
\text { Deviation }\end{array}$ \\
\hline \multirow{2}{*}{$\begin{array}{l}\text { Treinar e desenvolver a capacidade de } \\
\text { vendas }\end{array}$} & Brasileiro & 0,023 & 3,03 & 1,426 \\
\hline & Estrangeiro & & 2,49 & 1,040 \\
\hline \multirow{2}{*}{$\begin{array}{l}\text { Criar uma melhor imagem de minha } \\
\text { empresa }\end{array}$} & Brasileiro & 0,047 & 4,48 & ,724 \\
\hline & Estrangeiro & & 4,17 & 891 \\
\hline \multirow{2}{*}{$\begin{array}{l}\text { Obter vantagem em relação aos } \\
\text { concorrentes que não participam desta feira }\end{array}$} & Brasileiro & 0,001 & 4,10 & ,803 \\
\hline & Estrangeiro & & 3,43 & 1,313 \\
\hline \multirow[t]{2}{*}{ Observar as tendências do mercado } & Brasileiro & 0,012 & 4,43 & ,858 \\
\hline & Estrangeiro & & 3,37 & 1,165 \\
\hline \multirow[t]{2}{*}{ Motivar os clientes } & Brasileiro & 0,014 & 3,59 & 1,323 \\
\hline & Estrangeiro & & 3,80 & ,933 \\
\hline \multirow[t]{2}{*}{ Motivar ao pessoal de minha empresa } & Brasileiro & 0,009 & 3,38 & 1,237 \\
\hline & Estrangeiro & & 2,83 & ,822 \\
\hline \multirow{2}{*}{$\begin{array}{l}\text { Tomar nota de detalhes técnicos de } \\
\text { produtos concorrentes }\end{array}$} & Brasileiro & 0,015 & 3,07 & 1,507 \\
\hline & Estrangeiro & & 2,89 & 1,183 \\
\hline
\end{tabular}

Fonte: Dados da pesquisa. 
Ademais, as empresas brasileiras consideram a participação em feiras internacionais um fator de motivação para o seu corpo de vendas, talvez pelo fato de que viajar internacionalmente não é muito comum nessas empresas, diferentemente das empresas estrangeiras, principalmente as europeias, que viajam com maior frequência, motivando seus clientes.

\section{Conclusão}

Os esforços da empresa em atingir canais de distribuição e consumidores-alvo pormeio decomunicações, tais comovendas pessoais, propaganda, relações públicas e marketing direto são chamados de mix de promoção, e a utilização dos seus elementos depende da estratégia que a empresa se propõe a alcançar. A atividade internacional que mais fortemente está associada ao aumento da competitividade exportadora da empresa é a participação assídua em feiras internacionais, nas quais o administrador conhece os seus concorrentes e clientes, refletindo numa visão mais ampla do mercado global.

Neste artigo, o objetivo foi identificar as principais motivações que levam os expositores brasileiros e estrangeiros em feiras internacionais a participarem desses eventos, comparando também se há diferenças nas motivações de empresas brasileiras e internacionais. Os resultados indicam que as principais motivações para a participação em feiras internacionais estão relacionadas à melhoria da imagem da empresa, estabelecimento de parcerias e venda de produtos. As motivações consideradas menos importantes envolvem a participação em eventos paralelos, tais como seminários e palestras, fotografar concorrentes e a busca por produtos para representar.

$\mathrm{Na}$ análise fatorial, as 29 motivações diferentes foram resumidas a cinco fatores, a saber: fortalecimento da imagem e relacionamento; busca de vantagem competitiva; motivação da equipe e análise da concorrência; busca de novos negócios e parcerias; e relacionamento com fornecedores. 
Verifica-se que os expositores brasileiros têm menos experiência do que os estrangeiros na participação em feiras e quantidade de viagens internacionais. Ao comparar as médias das motivações com o teste $T$, verifica-se que os expositores brasileiros consideram mais importante do que os estrangeiros o treinamento da equipe de vendas e a sua motivação, a criação de uma melhor imagem, a obtenção de vantagem competitiva em relação aos concorrentes que não estão expondo, e a aquisição de informações técnicas da concorrência. Por sua vez, os estrangeiros consideram mais importante do que os brasileiros a motivação dos clientes durante a participação em feiras internacionais.

Esses resultados podem auxiliar futuros estudos na academia, assim como ajudar órgãos de fomento na formulação de atividades durante as exposições que atendam às expectativas dos participantes, tais como rodadas de negócio, projetos compradores e maior divulgação das empresas participantes.

Para pesquisas futuras, sugere-se a aplicação do questionário elaborado no artigo, objetivando comparar expositores de dois países distintos, o que poderia possibilitar uma melhor análise comparativa entre as motivações, de acordo com as diferenças culturais.

\section{Referências}

AULAKH, P. S.; KOTABE, M.; TEEGEN, H.. Export Strategies and Performance of Firms from Emerging Economies: evidence from Brazil, Chile and Mexico. Academy of Management Journal, New York, USA, v. 43, n. 3, Jun, 2000.

BARNEY, J. Firm Resources and sustained competitive advantage. Journal of Management, South Carolina , USA, v. 17, n. 1, p. 99-120, Mar. 1991.

\section{Gaining and Sustaining Competitive Advantage. New}

Jersey: Prentice Hall, 2002. 
BRITTO, R. P.. Competição Global: uma contribuição para o estudo da competitividade da indústria paulista. 2006. 206f. Dissertação (Mestrado em Administração) - Programa de Pós-Graduação em Administração da FEA/USP. São Paulo: FEA/USP, 2004.

CONDO, A.. Internationalization of firms based in developing economies. USA: Harvard University, 2000.

COOPER, D. R.; SCHINDLER, P. S. Métodos de Pesquisa em Administração. Porto Alegre: Bookman, 2003.

CZINKOTA, M. R.; RONKAINEN, I. A.; DONATH, B.. Mastering Global Markets: strategies for today's trade globalist. Stanford: Thomson Learning, 2004.

GABRIELSSON, M.; KIRPALANI, V. H. M.; LOUSTARINEN, R. Multiple Channel Strategies in the European Personal Computer Industry. Journal of International Marketing, Chicago, USA, v. 10, n. 3, p. 7395, Sept. 2002.

GOVINDARAJAN, Vijay, GUPTA, Anil K. Fixando uma direção no novo ambiente global. In: FINANTIAL TIMES. Dominando os Mercados Globais. 1.ed. São Paulo: Makron, 2001.

HANSEN, K. The dual motives of participants at international trade shows: An empirical investigation of exhibitors and visitors with selling motives. International Marketing Review, West Yorkshire, England, v. 13, n. 2, p. 39-53, 1996.

K. Measuring performance at trade shows: Scale development and validation. Journal of Business Research, Amsterdam, v. 57, n.1, p.1-13, Jan. 2004.

HOSHEN, N. Meeting the right visitors on your stand. International Trade Forum, Geneva, OLHAR v. 25, n. 3, p. 14-17, 33-34, July.-Sept. 1989.

HITT, M. A.; IRELAND, R. D.; HOSKISSON, R. E. Administração Estratégica. 1. ed. Thomsom: São Paulo, 2002. 
JOHANSON, J.; VAHLNE, J.. The internationalization process of the firm - a model of knowledge development and increasing foreign markets commitments. Journal of International Business Studies, New York, USA, v. 8, n.1, p. 23-32, Spring - Summer, 1977.

KEEGAN, W.; GREEN, M. Princípios de Marketing Global. São Paulo: Saraiva, 1999.

KEEGAN, W. Marketing Global. 7. ed. São Paulo: Prentice Hall, 2005. LEVITT, T. The Globalization of Markets. Harvard Business Review, Massachusetts, USA, v. 25, n. 3, pages 17-19, Autumn (Fall) 1983. MAXWELL, S. An expanded price/brand effect model: a demonstration of heterogeneity in global consumption. International Marketing Review, West Yorkshire, v. 18, n. 3, p. 325-343, 2001.

MORGAN, R. M.; HUNT, S. D. The Commitment-trust Theory of Relationship Marketing. Journal of Marketing, Chicago, v. 58, p. 2038, July, 1994.

MORIARTY, R. T.; MORAN, U. Managing Hybrid Marketing Systems. Harvard Business Review, Massachusetts, v. 68, n.6, p. 146-157, Nov.-Dec.1990.

PALACIOS, Tomás Manuel B., SOUSA, José Manuel M. de. Estratégias de Marketing Internacional. 1 ed. São Paulo: Atlas, 2004.

PORTER, M. E. Competição. Estratégias Competitivas Essenciais. 6 ed. Rio de Janeiro: Campus, 1999.

PRAHALAD, C. K.; HAMEL, G. The Core Competence of the Corporation. Harvard Business Review, Massachusetts, p. 79-91, May./ Jun.1990.

QUELCH, John A; KLEIN, Lisa R. The Internet and International Marketing. Sloan Management Review. Massachusetts, v. 37, n. 3, p. 60-75, Spring 1996. 
SETHURAMAN, R.; ANDERSON, J. C.; NARUS, J. A. Partnership Advantage and Its Determinants in Distributor and Manufacturer Working Relationships. Journal of Business Research, Amsterdam, v. 17, n. 4, p. 327-347, Dec., 1988.

SETUBAL, J. B. S.; SOUZA, Y. S. de. Feiras setoriais e seu potencial para a aprendizagem organizacional: um estudo sobre produtores de componentes de calçados do vale do rio dos sinos. Teoria e Evidência Econômica, Passo Fundo, v.12, n.23, p. 129-155, nov. 2004.

Disponível em: <http://www.upf.br/cepeac/download/rev_n23_2004_ art6.pdf>. Acesso em: 5.jun. 2006.

SIMONSON, I.; NOWLIS, S.; LEMON, K. The Effect of Local Consideration Sets on Global Choice Between Lower Price and Higher Quality. Marketing Science, Maryland, v. 12, n. 4, p. 357-377, Sept., 1993.

SMITH, T. M.; SMITH, P. M.. Distributor and end-user trade show attendance objectives: An opportunity for adaptive selling. Forest Products Journal, Georgia, v. 49, n. 1, p. 23-29, Jan. 1999.

SMITH, T. M.; HAMA, K.; SMITH, P. M. The effect of successful trade show attendance on future show interest: exploring Japanese attendee perspectives of domestic and offshore international events. The Journal of Business and Industrial Marketing, West Yorkshire, v. 18, n. 4/5, p. $403-418,2003$.

SUSTAR, B.; SUSTAR, R.. Managing Marketing Standardization in a Global Context. Journal of American Academy of Business. New York, v. 7, n. 1, p. 302-309, Sept. 2005.

THEODOSIOU, M.; KATSIKEAS, C. S. Factors Influencing the Degree of International. Pricing Strategy Standar, Chicago, v. 9, n. 3, p. 1-18, 2001.

URDAN, F. T.; URDAN, A. T. Gestão do Composto de Marketing.

São Paulo: Atlas, 2006 
VRONTIS, D.; KITCHEN, P. J. Entry methods and international marketing decision making: an empirical investigation. International Journal of Business Studies, New York, v.. 13, n. 1, p. 87-110, 24, June 2005.

WARD, James J. Product and promotion adaptation by European firms in the U.S. Journal of International Business Studies (pre-1986), New York, v. 4, n. 1, p. 78, Spring 1973.

WILD, J. J.; WILD, K. L. HAN, J. C. Y. International Business. New Jersey: Prentice-Hall, 2006.

WHITE; Gregory K. International online marketing of foods to US consumers. International Marketing Review, West Yorkshire, England, v. 14, n. 5, p. 376-384, 1997.

WHITELOCK, Jeryl. Global Marketing and the case of international product standardization. European Journal of Marketing, West Yorkshire, England, v. 21, n.9, p.32 - 44, 1987.

Artigo recebido em: 11/10/2015 Aprovado em: 15/12/2015 